\title{
Immunoelectrophoretic studies on human small intestinal brush border proteins: cellular alterations in the levels of brush border enzymes after jejunoileal bypass operation
}

\author{
H SKOVBJERG, E GUDMAND-HØYER, O NORÉN, AND H SJÖSTRÖM
}

From the Department of Biochemistry C, The Panum Institute, Medical-gastroenterological Department C, and Surgical-gastroenterological Department D, Herlev Hospital, University of Copenhagen, Denmark

in

SUMMARY The amounts of lactase (EC 3.2.1.23), sucrase (EC 3.2.1.48), maltase (EC 3.2.1.20), microvillus aminopeptidase (microsomal EC 3.4.11.2), and dipeptidyl peptidase IV (EC 3.4.14. $\times$ ) in biopsies from proximal jejunum and distal ileum were studied by quantitative crossed immunoelectrophoresis and enzymatic assays in obese patients one and six months after jejunoileal bypass operation and compared with peroperative levels. They were related to DNA and protein content. The protein/DNA ratio fell $28-43 \%$ postoperatively. Except for ileal lactase and sucrase all enzymes showed decreased levels when expressed per $\mathrm{mg}$ protein and an even more pronounced decrease when related to DNA. Lactase and sucrase levels in ileum were increased or unchanged. A constant correlation between the amount of immunoreactive enzyme protein and enzymatic activity was shown for all enzymes except maltase. The results suggest that the bypass operation is followed by an increased amount of enterocytes devoid of or low in enzymatic activity and protein content. The amounts of lactase and sucrase in ileum are increased in relation to the other enzymes. No immunoreactive enzymes with zero or depressed activity were detected.

Jejunoileal bypass operation frequently used in the treatment of morbid obesity results in malabsorption and weight loss. The increase in length and mucosal surface of the functioning shunt seems to be important for the weight stabilisation that usually occurs 12 to 18 months postoperatively. Increase of villus height and epithelial cell hyperplasia has been described after the operation. ${ }^{12}$ Changes in the specific activity of some of the brush border enzymes (disaccharidases and peptidases) which play an important role in the final digestion have been described, ${ }^{134-6}$ but the results are conflicting, probably because not only the cellular enzyme content but also the mucosal protein change postoperatively.

The reported changes in brush border enzyme activity can be caused by an alteration in the relative number of enterocytes or by a change in enzymatic activity at a cellular level. Such changes might be due

Received for publication 6 February 1980 to an altered amount of active enzyme molecules in the cells, or to the presence of more or less active enzyme molecules. Experimental studies on bypass operated rats ${ }^{7}$ have shown an increase in the DNA content per segment small intestine and a falling activity of brush border enzymes expressed per mg DNA indicating an increased amount of cells devoid of or low in enzymatic activity. These cells appear either as crypt cells or immature cells on the villi. Corresponding studies on human intestine have not been undertaken.

The present study investigates the cellular changes in the small intestinal brush border enzymes by the use of quantitative immunoelectrophoresis and DNA measurement in combination with measurements of enzymatic activity and protein. Quantitative immunoelectrophoresis, which earlier has been shown to be a valuable method in the study of human brush border enzymes, ${ }^{8}$ gives an expression of the amount of enzyme protein independent of the enzymatic activity. This enables an estimation of 
possible enzyme molecules with altered enzymatic activity. Moreover, changes in the internal relations between the enzymes measured can be more precisely determined, as they are quantified on the same immunoelectrophorectic plate. The method also, for the first time, allows changes occurring in the amount of brush border maltase to be estimated, as the enzymatic estimation of maltase activity also includes the activity of at least the sucrase-isomaltase complex.

\section{Methods}

PATIENTS

Twenty patients having jejunoileal shunt operation performed as a part of The Danish Obesity Project were investigated. Eleven patients were operated according to Payne and De Wind ${ }^{9}$ with $37.5 \mathrm{~cm}$ jejunum and $12.5 \mathrm{~cm}$ ileum (type I) and nine patients with $12.5 \mathrm{~cm}$ jejunum and $37.5 \mathrm{~cm}$ ileum (type II) left in continuity. Peroperative biopsies from the points of division-that is, proximal jejunum and distal ileum-were obtained in all patients. One to two and six to eight months postoperatively peroral biopsies were taken $25 \mathrm{~cm}$ below the ligament of Treitz-that is, jejunal biopsies from patients with type I and ileal biopsies from patients with type II operation. Nine patients with type I and seven with type II operation had biopsies taken one to two months postoperatively, while nine patients with type I and six with type II operation had biopsies taken six to eight months postoperatively. All biopsies were frozen in dry ice immediately after removal.

\section{TECHNIQUE}

From the peroperative biopsies mucosal samples (3-16 mg) were obtained by careful scraping. The
Fig. 1 Changes in amount of enzyme protein for each patient estimated in crossed

immunoelectrophoresis as area under the precipitate per $m g$ DNA at operation, one to two and six to eight months after jejunoileal shunt operation. Jejunal values are from patients with type I operation, ileal values from patients with type II operation. NS: not significant. The $\mathrm{P}$ values are obtained by testing the postoperative values against the peroperative values. Interrupted lines: in these patients the one to two months postoperative biopsies were not taken.

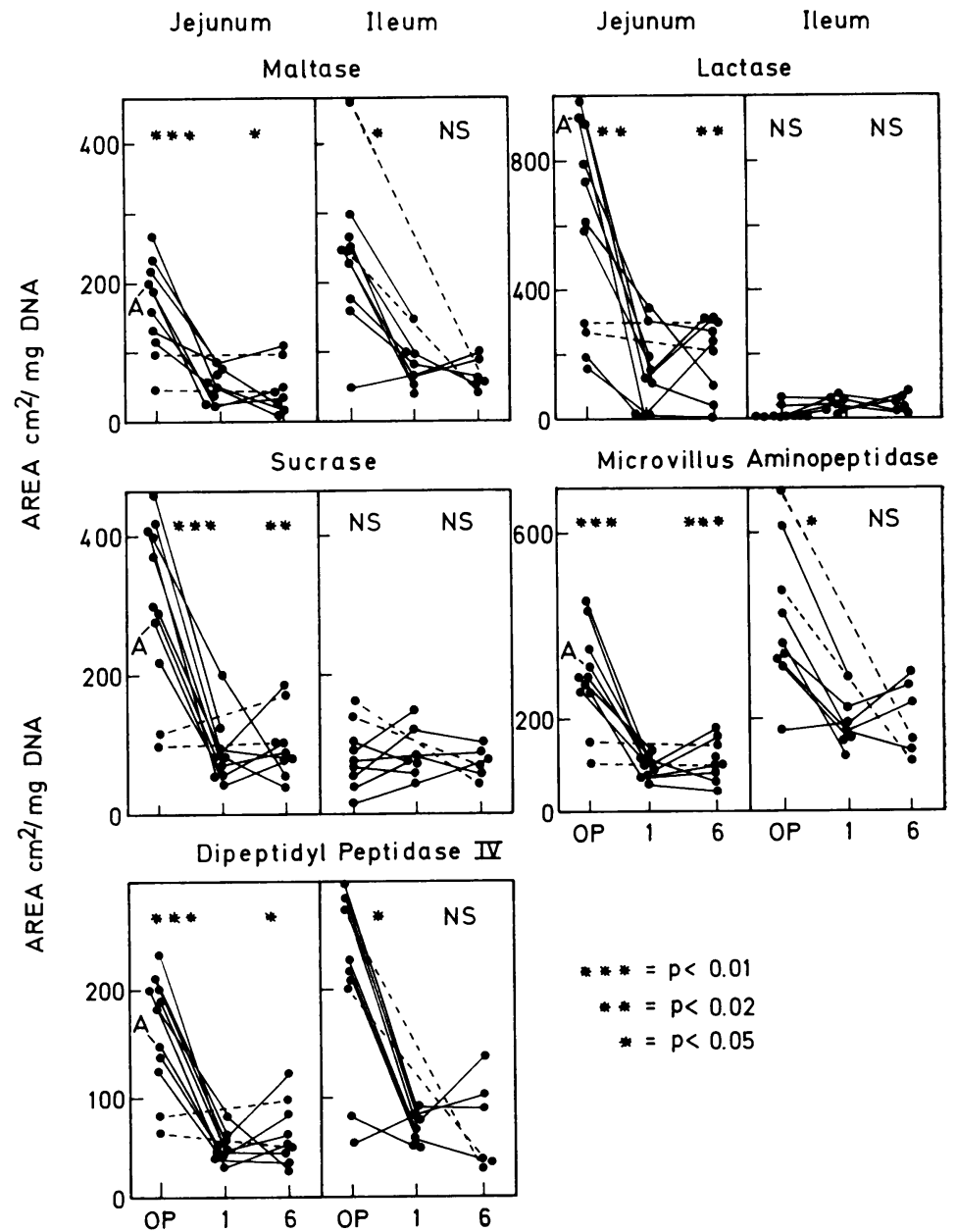




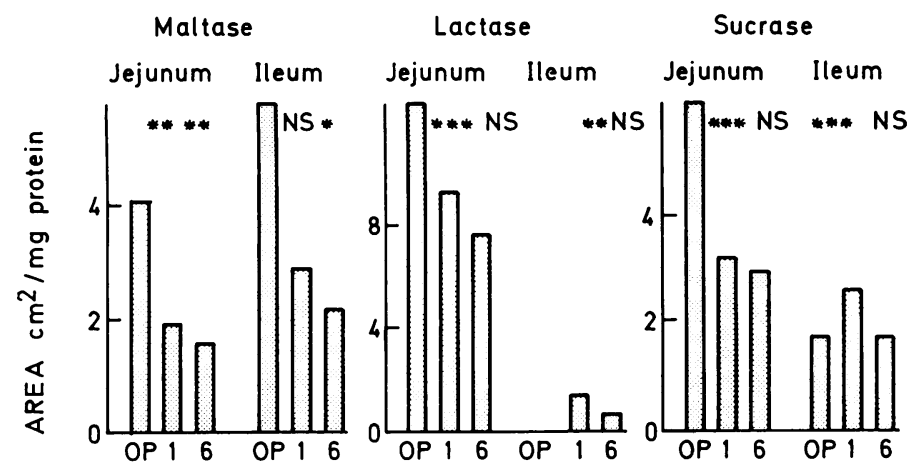

\author{
Fig. 2 Changes in amount of enzyme \\ protein for each patient estimated in \\ crossed immunoelectrophoresis as \\ area under the precipitate per $\mathrm{mg}$ \\ protein at operation, one to two and \\ six to eight months after jejunoileal \\ shunt operation. Jejunal values are \\ from patients with type I operation, \\ ileal values from patients with type If \\ operation. The bars represent the \\ median values. NS: not significant. \\ The $P$ values are obtained by testing \\ the postoperative values against the \\ peroperative values.
}

mucosal material was then handled as the peroral biopsies. Each biopsy was homogenised and the brush border proteins solubilised and quantified in crossed immunoelectrophoresis as earlier described. ${ }^{8}$ To summarise briefly: each sample was homogenised in $40 \mu \mathrm{l}$ of a $2 \%$ Triton X-100 solution and incubated for one hour at $4^{\circ} \mathrm{C}$. Papain at a final concentration of $2.5 \mathrm{mg} / \mathrm{ml}$ was added and $15 \mu \mathrm{l}$ removed for enzymatic analysis. The rest of the homogenate was incubated for 15 minutes at $37^{\circ} \mathrm{C}$ and subsequently centrifuged at $50.000 \times g$ for two hours. The supernatant was analysed in crossed immunoelectrophoresis. The precipitates, earlier identified by enzymatic staining, ${ }^{10}$ were stained by Coomassie Brillant Blue 250 and their areas expressed in $\mathrm{cm}^{2}$ by use of an electronic integrator.

Lactase (EC 3.2.1.23), sucrase (EC 3.2.1.48), and maltase activities were assayed in the homogenate using their corresponding disaccharides as substrates. ${ }^{11}$ The activities of microvillus aminopeptidase (microsomal, EC 3.4.11.2) and dipeptidyl peptidase IV (EC 3.4.14. $\times$ ) were determined using L-alanine-p-nitroanilide and glycyl-L-proline-pnitroanilide as substrate respectively. ${ }^{10}$ As a control of the solubilisation procedure the microvillus aminopeptidase activity was determined in the pellet. The protein concentration of the homogenate was measured ${ }^{12}$ in a small sample taken before addition of papain using bovine serum albumin as a standard. DNA concentration was measured using the fluorometric method of Kissane and Robins. ${ }^{13}$ Calf thymus DNA was used as a standard. Extraction of lipids was omitted, as it resulted in irreproducible loss of material and as the contribution of fluorescence from lipids in the homogenate was shown to be less than $8 \%$ of the measured value. The statistical evaluations were performed with the Mann-Whitney U test and the Wilcoxon test for paired data.

\section{Results}

As shown earlier ${ }^{8}$ the solubilisation procedure releases the studied enzymes almost completely from the brush border membranes. The mean rest activity of microvillus aminopeptidase in the pellet after solubilisation was for each patient group $2 \%$ (range $0-5 \%$ ) of the total activity. The protein/DNA ratio in the peroperative biopsies obtained by mucosal scrapings was found to be of the same magnitude as in peroral biopsies from the ligament of Treitz in patients without gastrointestinal disease. This indicates that the mucosal scrapings are comparable with the peroral biopsies where their content of villi and crypt cells is concerned.

Peroperative sucrase and lactase levels as measured by immunoelectrophoresis and enzymatic activity were significantly greater $(\mathbf{P}<0.05)$ in jejunal than 
in ileal biopsies. The levels of maltase, microvillus aminopeptidase, and dipeptidyl peptidase IV seemed lower in proximal jejunum than in distal ileum but the differences were not statistically significant.

The variations in enzyme protein per mg DNA for each patient for maltase, sucrase, lactase, microvillus aminopeptidase, and dipeptidyl peptidase IV one to two and six to eight months after operation, compared with the peroperative levels, are seen in Fig. 1. In jejunum all the measured enzymes decreased in parallel during the first postoperative months and remained significantly lower than peroperatively six to eight months after the operation. In ileum the levels of lactase and sucrase were not significantly changed during the study, while the other enzymes were decreased in parallel during the first postoperative months and remained decreased, though not significantly, six to eight months postoperatively.

When expressed as the area under the precipitate per $\mathrm{mg}$ protein (Fig. 2) all enzymes in jejunum tended to decrease. In ileum, lactase and sucrase increased while the other enzymes decreased almost in parallel.

For all the enzymes studied, except maltase, there was a close correlation between enzymatic activity and amount of enzyme protein irrespective of decreasing or increasing postoperative activity (Fig. 3).

Figure 4 exemplifies the results by showing the electrophoretic patterns in jejunal biopsies from the
Fig. 3 The amount of enzyme protein expressed as area under the precipitate versus the enzymatic activity. Some (crowded) points represent more than one patient. Five postoperative values of dipeptidyl peptidase IV were omitted, as the enzymatic analysis failed.
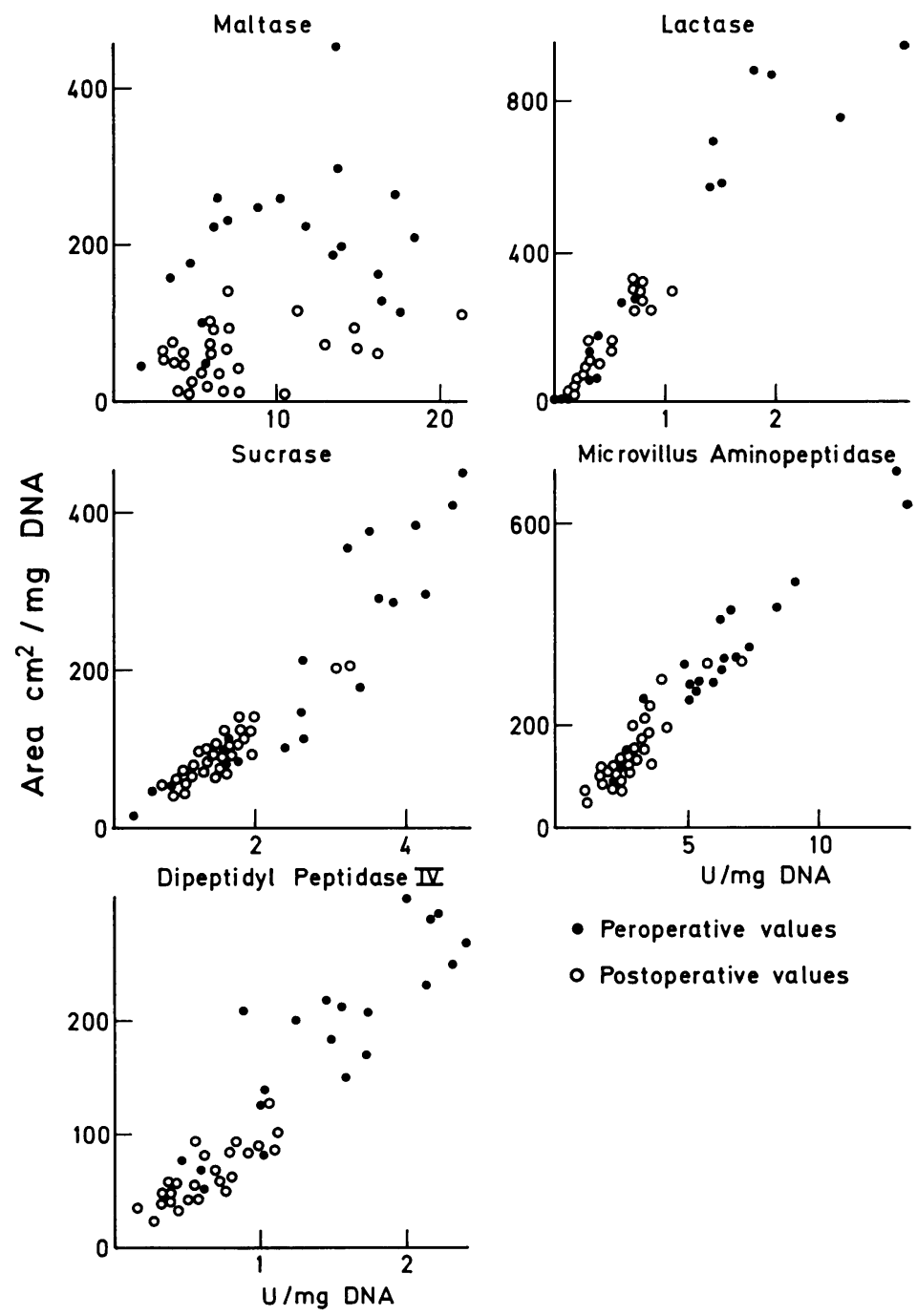

- Peroperative values

- Postoperative values 


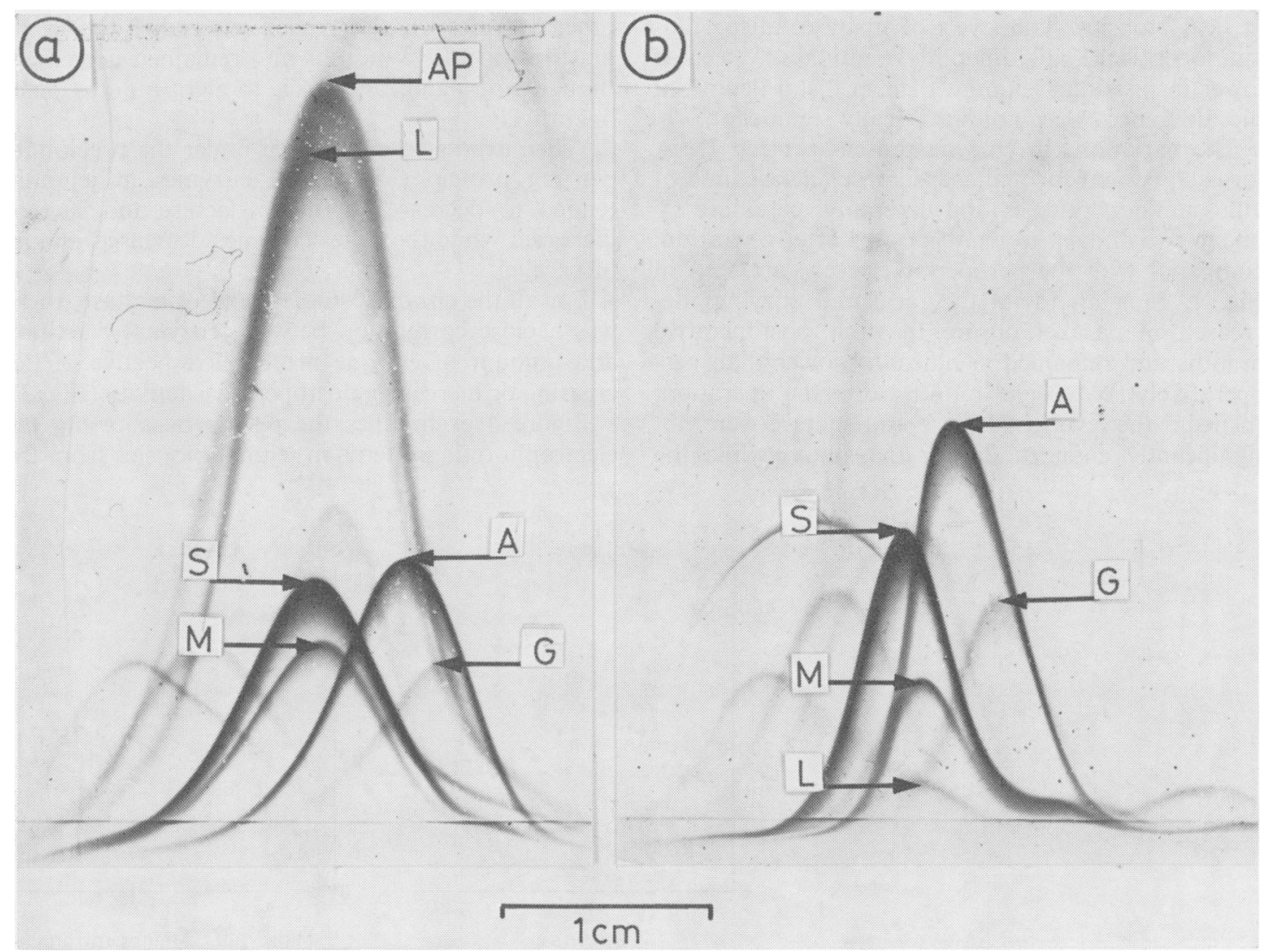

Fig. 4 Crossed immunoelectrophoresis of biopsies taken from the proximal part of jejunum (a) during operation, (b) one month after operation from patient $A$. The IgG concentration in the gel was $30 \mu \mathrm{g} / \mathrm{cm}^{2}$. The amount of antigen is equivalent to 4 and $15 \mu \mathrm{g} D N A$ respectively. L: lactase-phlorizin hydrolase. S: sucrase-isomaltase. M: maltase. A: microvillus aminopeptidase. G: dipeptidyl peptidase IV. AP: alkaline phosphatase (this precipitate is visible only after enzymatic staining).

same patient (type I operation) taken at operation and one month postoperatively (marked in Fig. 1 by A). This patient had a marked fall in lactase $(99 \%)$,

Table Mean values for ratio $\mathrm{mg}$ protein/mg DNA at operation, one to two months and six to eight months postoperatively for jejunum and ileum*

\begin{tabular}{llll}
\hline & Operation & \multicolumn{2}{l}{ Postoperatively $($ months) } \\
\cline { 3 - 4 } & & $1-2$ & $6-8$ \\
\hline \multirow{3}{*}{ Jejunum } & $45 \cdot 8$ & $26 \cdot 1$ & $29 \cdot 2$ \\
& $(19 \cdot 9-94 \cdot 3)$ & $(16 \cdot 6-37 \cdot 3)$ & $(13 \cdot 5-49 \cdot 3)$ \\
& $\mathrm{n}=18$ & $\mathrm{n}=9$ & $\mathrm{n}=9$ \\
& & $\mathrm{P}<0 \cdot 01$ & $\mathrm{P}<0 \cdot 02$ \\
Jeum & $47 \cdot 8$ & $27 \cdot 2$ & $34 \cdot 5$ \\
& $(32 \cdot 3-71 \cdot 3)$ & $(22 \cdot 9-34 \cdot 1)$ & $(20 \cdot 7-51 \cdot 0)$ \\
& $\mathrm{n}=17$ & $\mathrm{n}=7$ & $\mathrm{n}=6$ \\
& & $\mathrm{P}<0 \cdot 02$ & $\mathrm{NS}$ \\
\hline
\end{tabular}

*Numbers in parentheses are ranges. The $P$ values apply to differences between operation and one to two or six to eight months postoperati .ely. NS: not significant. while the other enzymes were all reduced by approximately $75 \%$ one month postoperatively compared with the operative level.

The Table shows the relation between protein and DNA content in the biopsies. The $28-43 \%$ fall in the ratio postoperatively is of the same magnitude as found in the small intestine from bypass operated rats. $^{7}$

\section{Discussion}

In the present study changes in the amount of different brush border enzymes have been examined in relation to changes in DNA and protein content.

The $28-43 \%$ fall in the protein/DNA ratio indicates that the protein content in the average enterocyte is diminished postoperatively. An increased number of dividing crypt cells increasing the average DNA content in the cells might cont- 
tribute to the decreased ratio but could not account for all of it. The reduced amount of protein in the enterocytes is in accordance with the findings of Danø et al. ${ }^{14}$ and is probably due to the postoperative protein malabsorptive state. ${ }^{1516}$

The almost parallel decrease of all enzymes in jejunum per mg DNA indicates a decreased amount of enzyme per cell. Morphological studies in rat and human ${ }^{1317}$ have shown an increased amount of enterocytes on the villi after bypass operation, while no alteration in the proportion of enterocytes to the total cell number has been described. ${ }^{1317}$ The falling enzyme activity per cell indicates the existence of a significant number of enterocytes devoid of or low in enzyme content. Whether the patients in addition to an increased migration rate of the enterocytes ${ }^{17}$ and increased cell proliferation ${ }^{18}$ have an increased turnover rate of the enterocytes cannot be settled in this study.

In ileum the levels of lactase and sucrase were unchanged during the period that was studied, while the levels of maltase, microvillus aminopeptidase, and dipeptidyl peptidase IV were decreased almost in parallel when expressed per mg DNA. This indicates that lactase and sucrase at the cellular level are increased in relation to the other enzymes, and it suggests that these disaccharidases are regulated independently of the other enzymes. An explanation might be that there is a relatively increased synthesis of lactase and sucrase due to enhanced intraluminal stimulation by lactose and sucrose, because the short functioning jejunum $(12.5 \mathrm{~cm})$ in these patients does not have enough capacity to split these disaccharides. This result is supported by the concept ${ }^{117}$ that the intraluminal nutrition exerts a major influence on the splitting and absorptive functions of the human small intestine. Alternatively, the catabolism of maltase, microvillus aminopeptidase, and dipeptidyl peptidase IV in ileum might be relatively increased postoperatively. Duodenal juice increases the turnover rate of some brush border enzymes. ${ }^{19} 20$ Theoretically, maltase, microvillus aminopeptidase, and dipeptidyl peptidase IVwhich, in contrast with lactase and sucrase, seem to have a higher peroperative level in the trypsin free ${ }^{21}$ distal ileum than in the proximal jejunum-might be more susceptile to the catabolic action of duodenal juice.

The patient presenting the extreme fall in jejunal lactase (Fig. 4) is an example of an individual variation. For unknown reasons the jejunal enterocytes in this patient temporarily seem to have a selective decreased level of lactase compared with the other enzymes.

Alterations in the amount of enzyme related to DNA reflect the fluctuations at a cellular level. This study therefore presents evidence for the fact that the increased amount of enterocytes shown in morphological studies are more or less deficient in enzymes. Also, when expressed per mg protein, the brush border enzymes show a tendency to decrease except for lactase and sucrase in the postoperative ileum. Whether the total amount of brush border enzymes per unit length intestine is changed postoperatively cannot be answered in this study. However, in experimental studies in rats it has been shown that, even if the enzymes decrease per mg protein and, even more pronouncedly, per mg DNA after jejunoileal shunt operation the amount of these enzymes per unit length intestine is increased.? This may also be true for the human.

In the present study we have also shown that, except for maltase, there is a close correspondance between the amount of immunoreactive enzyme protein and enzymatic activity before and after bypass operation. Thus we conclude that the decreased enzymatic activity is not caused by production of immunoreactive enzyme molecules with zero or decreased enzymatic activity. Provided that the solubilisation procedure also releases possible enzyme precursor molecules from intracellular particles we can also conclude that the suggested, increased population of immature cells on the villi does not contain an increased amount of immunoreactive enzyme precursors. Where maltase is concerned the precipitate area expresses directly the amount of this enzyme, while the enzymatic measurement represents the activities of both maltase and the sucrase-isomaltase complex. Thus the immunoelectrophoretic measurement of this enzyme was not expected to be correlated with the enzymatic activity.

The jejunoileal shunt operations were performed at surgical department D, Herlev Hospital, Denmark, as a part of the Danish Obesity Project. The authors are grateful to Ms D Anthonsen, Ms D Rasmussen, Ms M v Holstein, and the nursing staff of medicalgastroenterological Department C, Herlev Hospital, for skilful technical assistance. This work was supported by the Danish Medical Research Council (No. 512-10175), P Carl Petersens Fond (No. B 1076) and the Novo Foundation.

\section{References}

${ }^{1}$ Dudrick SJ, Daly JM, Castro G, Akhtar M. Gastrointestinal adaptation following small bowel bypass for obesity. Ann Surg 1977; 185: 642-7.

${ }^{2}$ Solhaug JH, Tvete S. Adaptive changes in the small intestine following bypass operation for obesity. A radiological and histological study. Scand J Gastroenterol 1978; 13: 401-8. 
${ }^{3}$ Iversen BM, Schjønsby H, Skagen DW, Solhaug JH. Intestinal adaptation after jejunoileal bypass operation for massive obesity. Eur J Clin Invest 1976; 6: 355-60. ${ }^{4}$ Stein TA, Wise L. Functional adaptation of the intestinal mucosal enzymes after jejunoileal bypass for morbid obesity. Am J Clin Nutr 1978; 31 : 1143-8.

${ }^{5}$ Gudmand-Høyer E, Asp NG, Skovbjerg H, Andersen B. Lactose malabsorption after bypass operation for obesity. Scand J Gastroenterol 1978; 13: 641-7.

${ }^{6}$ Asp NG, Gudmand-Høyer E, Andersen B, Berg NO. Enzyme activities and morphological appearance in functioning and excluded segments of the small intestine after shunt operation for obesity. Gut 1979; 20: $553-8$.

${ }^{7}$ McCarthy DM, Kim YS. Changes in sucrase, enterokinase, and peptide hydrolase after intestinal resection. The association of cellular hyperplasia and adaptation. J Clin Invest 1973; 52: 942-51.

${ }^{8}$ Skovbjerg H, Sjöström H, Norén $O$, GudmandHøyer E. Immunoelectrophoretic studies on human small intestinal brush border enzymes. A quantitative study of brush border enzymes from single small intestinal biopsies. Clin Chim Acta 1979; 92: 315-22.

${ }^{9}$ Payne JH, DeWind LT. Surgical treatment of obesity. Am J of Surg 1969; 118: 141-7.

${ }^{10}$ Skovbjerg $\mathrm{H}$, Norén $\mathrm{O}$, Sjöström $\mathrm{H}$. Immunoelectrophoretic studies on human small intestinal brush border proteins. A qualitative study of the protein composition. Scand J Clin Lab Invest 1978; 38: 723-9.

${ }^{11}$ Dahlqvist A. Assay of intestinal disaccharidases. Anal Biochem 1968; 22: 99-107.

${ }^{2}$ Wang CS, Smith RL. Lowry determination of protein in the presence of Triton X-100. Anal Biochem 1975; 63: 414-7.

${ }^{13}$ Kissane JM, Robins E. The fluorometric measurement of deoxyribonucleic acid in animal tissues with special reference to the central nervous system. J Biol Chem 1958; 233: 184-8.

${ }^{14}$ Danø P, Nielsen OV, Petri M, Jørgensen B. Jejunal morphology and mucosal enzyme activity following intestinal shunt operation for obesity. Scand J Gastroenterol 1976; 11: 129-34.

${ }^{15}$ Editorial. Intestinal adaptation and hepatic decompensation after jejunoileal bypass for morbid obesity. Nutr Rev 1977; 35: 43-5.

${ }^{16}$ Solhaug JH, Grundt I. Metabolic changes after jejunoileal bypass for obesity. Scand J Gastroenterol 1978; 13: $169-75$.

${ }^{17}$ Gleeson MH, Cullen J, Dowling RH. Intestinal structure and function after small bowel bypass in the rat. Clin Sci 1972; 43: 731-42.

${ }^{18}$ Barry RE, Barisch J, Bray GA, Sperling MA, Morin RJ, Benfield J. Intestinal adaptation after jejunoileal bypass in man. Am J Clin Nutr 1977; 30: 32-42.

${ }^{19}$ Alpers DH, Tedesco FJ. The possible role of pancreatic proteases in the turnover of intestinal brush border proteins. Biochim Biophys Acta 1975; 401: 28-40.

${ }^{20} \mathrm{~K}$ wong WKL, Seetharam B, Alpers DH. Effect of exocrine pancreatic insufficiency on small intestine in the mouse. Gastroenterology 1978; 74: 1277-82.

${ }^{21}$ Chung YC, Kim YS, Shadchehr A, Garrido A, MacGregor IL, Sleisenger MH. Protein digestion and absorption in human small intestine. Gastroenterology 1979; 76: 1415-21. 